\title{
Microstrip Array Antenna using Series-Corporate Feed for Navigation System
}

\author{
Taher Khalifa ${ }^{1}$, N.Ramli ${ }^{1}$, N.M. Sahar ${ }^{2}$ \\ ${ }^{1}$ Centre of Advanced Electrical and Electronics Systems (CAEES), \\ Faculty of Engineering and the Built Environment, SEGi University, Kota Damansara, Selangor, Malaysia. \\ ${ }^{2}$ Space Science Centre, Institute of Climate Change, Universiti Kebangsaan Malaysia, UKM Bangi, Selangor, Malaysia. \\ Article Info \\ Article history: \\ Received May 2, 2020 \\ Revised Sep 14, 2020 \\ Accepted Oct 2, 2020

\section{Keywords:} \\ High gain \\ Feed network \\ Radiation pattern \\ Circularly polarization \\ Navigation system

\begin{abstract}
In this paper, the proposed antenna consists of a single transmission line for 6-elements microstrip array antenna using Rogers RT5880 substrate material with a dielectric constant $\left(\varepsilon_{\mathrm{r}}\right)$ of 2.2 and thickness of $0.787 \mathrm{~mm}$ for navigation applications. The array structures of unequal patches placement are proposed with corporate feed line and $\mathrm{H}$-shaped configurations are employed on the substrate and used the microstrip feed line with a corporate feed network excited via $50 \Omega$ with T-junction method to control the feed for each group. 6elements microstrip array antenna has operated at the resonant frequency of 1.27 GHz was obtained between the frequency from $1.2663 \mathrm{GHz}$ to 1.2734 $\mathrm{GHz}$ where the S11-parameters of the structure designed and simulation below than $<-10 \mathrm{~dB}$. The analysis shows the antenna gain has increased $72.6 \%$ with high directivity as compared to single elements microstrip antenna. The radiation characteristics and other array parameters are evaluated with respect to the application requirements. However, circular polarization has obtained in 6-elements array antenna as the axial ratio is successfully achieved below than $-3 \mathrm{~dB}$. The antenna efficiency, the current distribution, VSWR, and S11-parameters of the proposed 6-elements CP microstrip array antenna have been presented and discussed in detail. The design methodology and the measurement results have been presented and discussed in this paper.
\end{abstract}

Copyright $@ 2020$ Institute of Advanced Engineering and Science. All rights reserved.

\author{
Corresponding Author: \\ Taher Khalifa \\ Centre of Advanced Electrical and Electronics Systems (CAEES), \\ Faculty of Engineering and the Built Environment, SEGi University, \\ Kota Damansara, 47810 Selangor, Malaysia \\ Email: tahersunossi@gmail.com
}

\section{INTRODUCTION}

Satellite navigation system uses satellites to provide information on geographical location [1]. The system allows small electronic receivers to determine their position (latitude, longitude, altitude and altitude) with high accuracy using time signals transmitted by satellite radio. The main motivation for the invention of satellite navigation systems is to develop a low profile and lightweight with excellent performance. The circularly polarized (CP) performance of antenna become the main characteristics in the global position system (GPS) due to higher probability of successful link [2]. Generally, the CP array antenna is designed based on the limited radiating patches and the feeding network. Feed networks techniques have been studied such as cross-aperture coupled [3], hybrid coupler [4, 5] and sequentially rotated feed [6] to obtain circular polarisation. In this array antenna, corporate feed is the most widely used feeding techniques [7] to fabricate the array antenna due to the incident power is equally splitting and distributing to the individual antenna elements. Antenna arrays have become one of the important options in the $\mathrm{CP}$ antenna. The specific current distribution can be achieved by the feeding mechanism and properly arranging the radiating elements [8]. The corporate feeding technique can provide power splits of $2 \mathrm{~K}$ (where $\mathrm{k}=2 ; 4 ; 8 ; 16 \ldots \ldots$ ). The patch 
elements are connected by using $\lambda / 4$ impedance transformers. The wavelength of $\lambda / 4$ above ground or on other surfaces with conducting abilities allow the radials to react as a near-perfect ground system catered for the electromagnetic field. At the same time, the antenna will experience a high radiation pattern. All these can be independently considered where the process of designing the array antenna can be separated by individual phases.

The reason is mainly due to the difficulty of designing a 3D feed network configuration at low frequencies while considering the return loss, bandwidth and gain behaviour [9]. The $2 \times 3$ element full metal corporate feed antenna array for the circular polarization application was proposed and close attention should be paid to both the polarised feed networks design and the fabrication process [10]. Currently, most of the circularly polarised antenna array studied are in the form of microstrip structures or printed circuits [11]. These 3D designs are preferred candidates because the routing of feed networks is a low profile [12]. Nevertheless, the downsides of these designs include significant losses at higher frequencies, surface waves excited on the substrate and limited power handling capacity [13]. Although such corporate feed arrangement can help in improving the operational bandwidth and the space available for the feed network is intrinsically limited by the radiating element $[14,15]$.

Series-corporate feed network also is reported [16] to perform circularly polarization. This means that the elements will experience spatial distribution and to ensure optimal performance, the phases and magnitudes at every element must be tuned accordingly [17]. While the rectangular waveguide is of corporate feed for wideband purposes [18-20]. Moreover, in order to reduce the long line effect from the series feed and extricate it from space limitation due to the radiating element with a $\mathrm{T}$-junction waveguide power divider to form a complete feed network [21]. The hybrid solution is applied here for designing $2 \times 3$ antenna array with circular polarization, broad bandwidth, high isolation and circular polarization characteristics $[22,23]$. These antennas reported in the literature have an excellent axial ratio which is less than $3 \mathrm{~dB}$ and good radiation performance, but expanding large-scale antenna. The stripline is arranged in a series feed form to excite all the radiation directly and retain its low loss at the resonant frequency [24].

In this paper, a series-corporate hybrid feed technique is implemented to design the circularly polarized feed networks. A low profile microstrip patch array that able to generate $\mathrm{CP}$ with high gain performances is designed. 6-elements of microstrip array antenna is compared with a single antenna to study the directivity and the gain There are certain factors involved in determining the radiation pattern, axial ratio and S11-parameters. The antenna design and result analysis are discussed in the following sections.

\section{ANTENNA DESIGN}

The proposed antenna of the rectangular single element patch antenna is designed using Rogers RT5880 substrate which is having a dielectric constant of $\varepsilon r=2.2$ and the tangent delta loss of $\tan \delta=0.0009$ $\mathrm{dB}$. The size of a single element antenna is $160 \times 160 \times 0.787 \mathrm{~mm} 3$ with the thickness of the substrate $\mathrm{h}=$ $0.787 \mathrm{~mm}$. The Rogers RT5880 substrate is chosen in order to meet the demand for high gain. On the top layer, the rectangular shaped radiating patch and the bottom side are layered with the full conducting ground plane as depicted in Figure 1(a). Further, the antenna element is excited by the electrical signal feed with a 50 $\Omega$ characteristics impedance microstrip antenna transmission line by using the formulas mentioned in [25].

$$
W=\frac{C_{0}}{2 f_{r}} \times \sqrt{\frac{2}{\varepsilon_{r}+1}}
$$

where.

$\mathrm{C}_{0}=$ Speed of Light in Free Space.

$f r=$ Resonance Frequency.

$\varepsilon_{r}=$ Permittivity Constant of Dielectric Substrate.

The length of a rectangular patch antenna is normally chosen in the range of $0.333 \lambda<\mathrm{L}<0.5 \lambda$. When the patch is excited by the line feed, a charge distribution was established on the ground plane and on the downside of the patch. The ground plane is negatively charged and the patch positively charged by the excitation. Attractive forces were generated between the ground plane, the patch and this produces fringe fields. This fringing effect is equivalent to an extension of the patch by a distance $(\Delta \mathrm{L})$. The effective dielectric constant (ereff) of the microstrip line is given by:

$$
\varepsilon_{r e f f}=\frac{\varepsilon_{r}+1}{2}+\frac{\varepsilon_{r}-1}{2} \times\left[1+12 \frac{h}{W_{p}}\right]^{-\frac{1}{2}}
$$


For $W / h>1$.

Calculate $(\Delta \mathrm{L})$ normalized length extension is given as substitute the value of (ereff, $W, h)$ :

$$
\frac{\Delta L}{h}=0.412 \times \frac{\left(\varepsilon_{\text {reff }}+0.3\right) \times\left(\frac{W_{p}}{h}+0.264\right)}{\left(\varepsilon_{\text {reff }}-0.258\right) \times\left(\frac{W_{p}}{h}+0.8\right)}
$$

The length of patch antenna $(L)$ calculate by:

$$
\mathrm{L}=L_{e f f}-2 \Delta L
$$

Substituting the value of ( $\varepsilon r e f f \& f r)$ :

where.

$$
L_{e f f}=\frac{V_{0}}{2 f_{r} \sqrt{\varepsilon_{r e f f}}}-2 \Delta L
$$

$V o=$ Velocity of Light $3 \times 10^{8} \mathrm{~m} / \mathrm{s}$.

The resonance frequency calculate by:

$$
f_{r}=\frac{C}{2 \mathrm{~W}} \times \sqrt{\frac{2}{\left(1+\varepsilon_{r}\right)}}
$$

The impedance $\left(Z_{0}\right)$ calculate by:

where.

$$
\begin{gathered}
Z_{o}=\operatorname{Rin} \cos ^{2}\left(\frac{\pi}{L_{p}}-d\right) \\
\lambda=\frac{C}{f_{r}}
\end{gathered}
$$

$\lambda=$ Wavelength.

$d=$ Inset distance from radiating edge.

Rin $=$ Resonance Input Resistance, when the patch is feeding at radiating edge.

For practical considerations, it is essential to have a finite and infinite ground plane that can be obtained if the size of the ground plane is greater than the patch dimensions by approximately six times of the substrate thickness all around the periphery. According to the design equations, the antenna dimensions are obtained. The ground plane dimensions calculate by:

$$
\begin{aligned}
& W_{g}=2 \times 6 h+W_{p} \\
& L_{g}=2 \times 6 h+L_{p}
\end{aligned}
$$

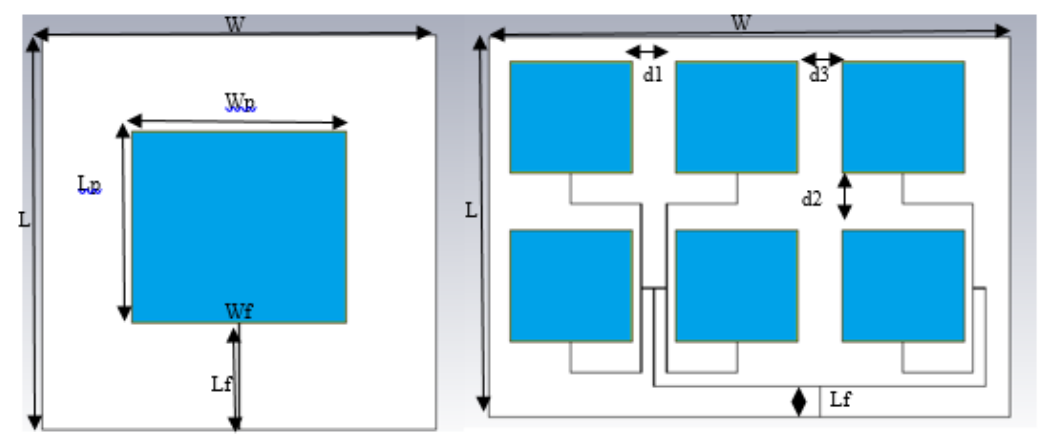

Figure 1. (a): Single element antenna. (b): 6-element microstrip antenna. 
In proposed the array design antenna, 6-elements of microstrip antenna is designed with width patch antenna is $86.97 \mathrm{~mm}$ and the length patch antenna is $79.80 \mathrm{~mm}$ by using a single microstrip feed line that is T-junction power divider. The corporate feed branch is proposed at the $50 \Omega$ impedance where the width and length of the feed line is remained from single element. Middle series feed antenna with unbalanced radiating elements is proposed for different current distribution [26]. The antenna elements are arranged at separation less than wavelength accordingly as shown in Table 1. In this array antenna design, elements are arranged vertically using $\mathrm{d} 1$ and $\mathrm{d} 2$ while from edge to edge, each antenna of $\lambda / 2$ and $\mathrm{d} 3$ spacing between group arrays are applied. This dimension must be optimized to obtain the best performance as stipulated in the specification of this project. The dividing branches are designed with $200 \Omega$ impedance, where the radiating elements are placed in unbalance number which is $2 \times 2$ and $2 \times 1$ elements as shown in Figure 2(a).

There are four elements in the group is employed in left side meanwhile two elements are employed on the right side that can perform different power divider. Thus, a different impedance of microstrip feed alteration is connected via a quarter wavelength transformer. The H-shaped configuration on the left side for matching line is performed at $35.335 \Omega$ impedance and the dividing branches with quarter-wavelength are $70.07 \Omega$ impedance. In the right side, the center feed branch is $35.335 \Omega$ impedance and the dividing branches are $100 \Omega$ impedance as only two radiating elements are employed. This array configuration comprises a novel corporate feed architecture to perform circular polarization.

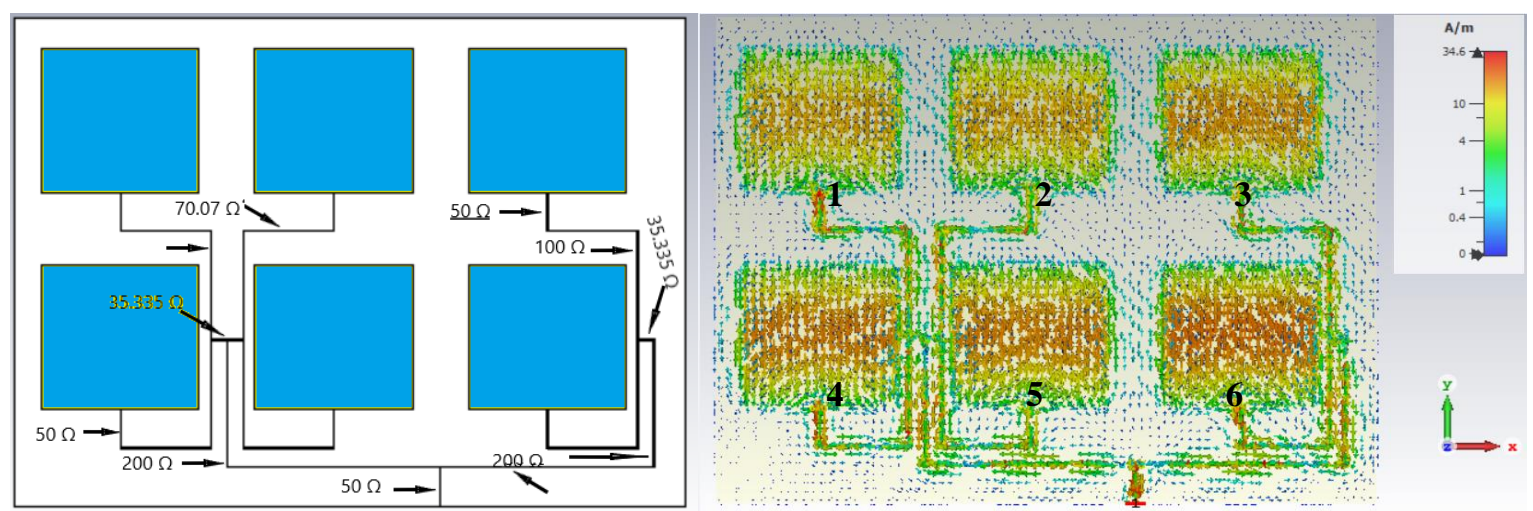

Figure 2. (a): 6-element array microstrip antenna. (b): Surface distribution currents.

Figure 2(b) exhibits the simulated current distribution for 6-elements array and the currents flow stronger on the left side as only 2 radiating patches are applied. However, more current distributed on patches 4, 5 and 6 as these patches are connected in short path from the main feed point. On the other hand, the area out of phase of current distribution performed as the current flow along the feedline. This contributes to the performance of circular polarization.

Table 1. Parameters of single element and 6-element array antenna.

\begin{tabular}{cccl}
\hline Parameter & $\begin{array}{c}\text { Single Element } \\
\text { Microstrip Antenna } \\
\text { Dimension }(\mathrm{mm})\end{array}$ & $\begin{array}{c}\text { 6-Element } \\
\text { Microstrip Antenna } \\
\text { Dimension (mm) }\end{array}$ & Description \\
\hline$W p$ & 86.97 & 86.97 & Width Patch \\
$W$ & 77.88 & 77.80 & Length Patch \\
$L$ & 160.0 & 370.0 & Width Substrate \\
$W f$ & 160.0 & 270.0 & Length Substrate \\
$L f$ & 2.44 & 2.43 & Width of Feed line \\
$h$ & 43.22 & 43.20 & Length of Feed line \\
$t$ & 0.787 & 0.787 & Thickness Substrate \\
$d 1$ & 0.035 & 0.035 & Thickness of Copper \\
$d 2$ & - & 31.03 & Horizontal Distance of Each Elements \\
$d 3$ & - & 40.20 & Vertical Distance of Each Elements \\
& - & 31.03 & Spacing between group Array \\
\hline
\end{tabular}

\section{RESULTS AND DISCUSSION}

Comparison between the simulated and measured results for the single element and 6-element microstrip array antenna are discussed in this section. The placement of radiating patches in array design has increased of antenna size, but improve the performance of the bandwidth, directivity and gain. Figure 3 shows the comparison S11-parameters of measured and simulated which is below $-10 \mathrm{~dB}$ for the proposed antenna design at the resonance frequency of $1.27 \mathrm{GHz}$. For the simulation results $\mathrm{S} 11=-26.52 \mathrm{~dB}$ is shown in Figure 3(a), that has been dropping to the negative value more than the measurement results of $S 11=-12.20$ 
$\mathrm{dB}$ with the narrow bandwidth of the simulation results of $\mathrm{BW}=6.86 \mathrm{MHz}$. The antenna gain and directivity of simulation results are $5.4 \mathrm{~dB}$ and $7.82 \mathrm{~dB}$ respectively.

For achieving the design of GPS antenna applications, the specification of the operating frequency and the substrate material used for 6-element array antenna was initially selected to be $1.27 \mathrm{GHz}$. As expected, the operating frequency $1.27 \mathrm{GHz}$ was obtained between the frequencies from $1.2691 \mathrm{GHz}$ to 1.2771 GHz, where the comparison between the simulation and the measurement results of S11-parameters for the structure designed lower than $-10 \mathrm{~dB}$ is shown in Figure 3(b). For the simulation results $\mathrm{S} 11=-40.78$ $\mathrm{dB}$ has been dropping to the negative value more than the measurement results of $\mathrm{S} 11=-18.31 \mathrm{~dB}$, this difference between them because, the SAM was poorly connected to the microstrip line feed. The bandwidth of the simulation results of bandwidth is $6.92 \mathrm{MHz}$.

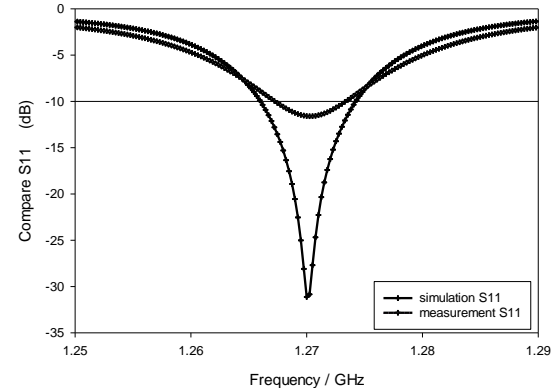

(a)

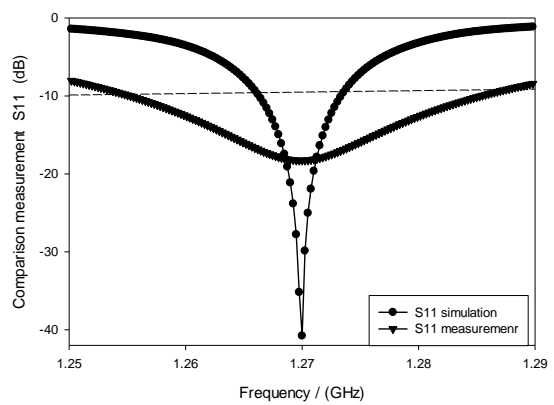

(b)

Figure 3. Comparison between simulation and measurement results of S11 for (a): single element, (b): 6element array.

Figure 4 shows the comparison between the measurement and simulation results for the radiation pattern of a single element microstrip antenna which are E-plane $\left(\mathrm{Phi}=0.0^{\circ}\right)$ and $\mathrm{H}$-Plane $\left(\mathrm{Phi}=90.0^{\circ}\right)$. The main lobe direction is $0.0^{\circ}$ degree and the angular width $3 \mathrm{~dB}$ is equal to $33.9^{\circ}$ degree. The side lobe level is equal to $-17.4 \mathrm{~dB}$ for the E-Plane $\left(\mathrm{Phi}=0.0^{\circ}\right)$. On the other hand, the main lobe direction is $90.0^{\circ}$ degrees and the angular width $3 \mathrm{~dB}$ is equal to $93.3^{\circ}$ degrees. The side lobe level is equal to $-13.6 \mathrm{~dB}$ for $\mathrm{H}$-plane $\left(\mathrm{Phi}=90^{\circ}\right)$ at the resonance frequency $1.27 \mathrm{GHz}$. The radiation pattern gain of a single element for the main lobe magnitude is equal to $5.4 \mathrm{~dB}$.

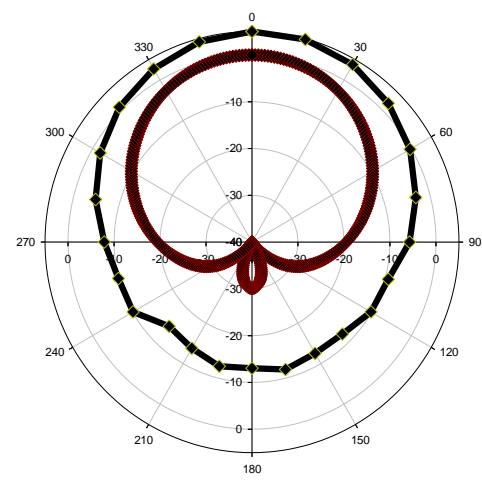

(a)

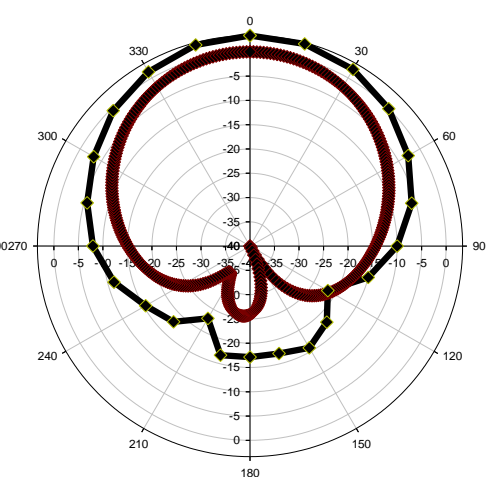

(b)

Figure 4. Comparison radiation pattern of simulated and measured results for single element. (a): E-Plane

$\left(\mathrm{Phi}=0.0^{\circ}\right)$. (b): H-Plane $\left(\mathrm{Phi}=90.0^{\circ}\right)$.

As compared to the measurement results of the radiation pattern for 6-element array antenna, the main lobe magnitude is equal to $10.11 \mathrm{~dB}$ as shown in Figure 5(a). The main lobe direction is $90.0^{\circ}$ degree and the angular width $3 \mathrm{~dB}$ is equal to $53.5^{\circ}$ degree. While the side lobe level is equal to $-24.8 \mathrm{~dB}$ for $\mathrm{H}$-Plane $\left(\mathrm{Phi}=90^{\circ}\right)$ at the resonance frequency $1.27 \mathrm{GHz}$. The radiation pattern gain for the 6-element of the main lobe magnitude is equal to $10.11 \mathrm{~dB}$ as shown in Figure 5. Moreover, the setups number even adds and the central setup was executed than the radiation pattern maximum is normal to array antenna of the $\mathrm{z}$-axis. The executed setup was not symmetrically located relative to the antenna center. Then the main lobes that deflect to the executed setup. In addition, the improved number of the radiation elements were increased with a high directional pattern of the radiation pattern. 


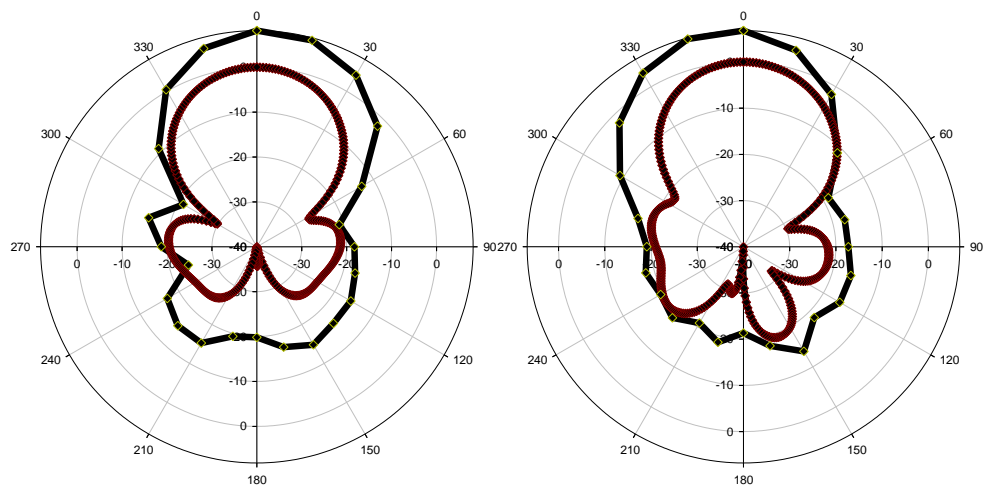

(a)

(b)

Figure 5. (a): Comparison radiation pattern of simulated and measured results for 6-element. (a): E-Plane $\left(\mathrm{Phi}=0.0^{\circ}\right)$. (b): H-Plane $\left(\mathrm{Phi}=90.0^{\circ}\right)$.

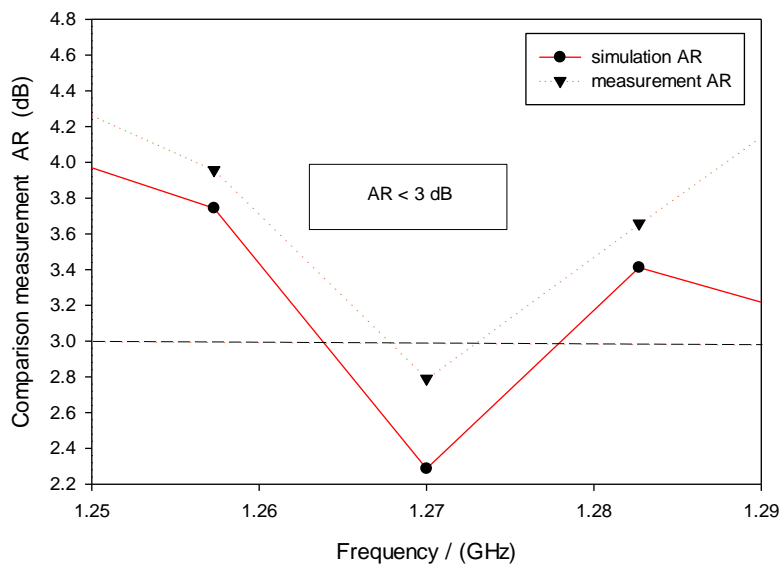

Figure 6. Measurement results of AR for 6-element array antenna.

Comparison between the measurement and simulation results for the axial ratio of 6-element microstrip array antenna as shown in Figure 6. The axial ratio has been lower than $3 \mathrm{~dB}$ between $0.0^{\circ}$ to $360.0^{\circ}$ of $\mathrm{AR}=0.53 \mathrm{~dB}$. The direction of a circularly polarized wave is determined by the rotation direction of the vector E-plane as it describes the right-hand circular polarization (RHCP) of the microstrip array antenna at the resonance frequency of $1.27 \mathrm{GHz}$

Table 2. Comparison between single element antenna and 6-element array antenna.

\begin{tabular}{lcccc}
\hline \multirow{2}{*}{ Parameters } & \multicolumn{2}{c}{ Single Element Microstrip } & \multicolumn{2}{c}{ 6-Element Array Microstrip } \\
& \multicolumn{2}{c}{ Antenna } & Antenna \\
\cline { 2 - 5 } & Simulation & Measurement & Simulation & Measurement \\
\hline S11 & $-26.52 \mathrm{~dB}$ & $-12.20 \mathrm{~dB}$ & $-40.78 \mathrm{~dB}$ & $-18.31 \mathrm{~dB}$ \\
Bandwidth & $6.86 \mathrm{MHz}$ & $8.23 \mathrm{MHz}$ & $6.92 \mathrm{MHz}$ & $29.72 \mathrm{MHz}$ \\
Gain & $5.40 \mathrm{~dB}$ & $4.70 \mathrm{~dB}$ & $10.11 \mathrm{~dB}$ & $8.11 \mathrm{~dB}$ \\
Directivity & $7.82 \mathrm{~dB}$ & $7.79 \mathrm{~dB}$ & $12.96 \mathrm{~dB}$ & $13.54 \mathrm{~dB}$ \\
VSWR & 1.09 & 1.48 & 1.10 & 1.65 \\
Polarization & $\mathrm{LP}$ & $\mathrm{LP}$ & RHCP & RHCP \\
Axial Ratio & - & - & $0.53 \mathrm{~dB}$ & $1.70 \mathrm{~dB}$ \\
\hline
\end{tabular}

\section{CONCLUSION}

In this paper, the measurement results of 6-element microstrip array antenna using Rogers RT5880 was improved and performed high gain. The increment of antenna gain has been achieved through the addition of radiation elements in the array antenna structure. From the measurement results, there was $72.6 \%$ increase of antenna gain after adding the 6 radiating elements to the proposed array antenna. For the directivity of the proposed array antenna, it is performed of $74 \%$ increase with a high directional pattern of the radiation pattern. On the other hand, circular polarization has been typically obtained, when an array antenna structure was excited using a series-corporate hybrid feed at the impedance $50 \Omega$. AR was performed lower than $3 \mathrm{~dB}$ with a wide angular range for the proposed array antenna. The thickness of the substrate makes it possible is to achieve a narrower antenna beamwidth and this supports the GPS applications as the 
angle between the half power beamwidth (HPBW) around $-3 \mathrm{~dB}$. This was improved for the matching impedance as well as reducing the substrate's active permittivity and where the percentage of an antenna efficiency of $51.48 \%$ at the center frequency of $1.27 \mathrm{GHz}$.

\section{ACKNOWLEDGMENTS}

The authors wish to thank Centre of Advanced Electrical and Electronics Systems (CASES), Faculty of Engineering and the Built Environment, SEGi University Kota Damansara, Malaysia and the Space Science Center (ANGKASA), Institute of Climate Change, University Kebangsaan Malaysia.

\section{REFERENCES}

[1] M. Khider, T. Jost, P. Robertson and E. Abdo-Sánchez, "Global navigation satellite system pseudorangebased multisensor positioning incorporating a multipath error model," IET Radar, Sonar \& Navigation, vol.7, no.8, pp. 881-894, 2013.

[2] X. Chen, D. Wu, L. Yang and G. Fu, "Compact Circularly Polarized Microstrip Antenna With Cross-Polarization Suppression at Low-Elevation Angle," IEEE Antennas and Wireless Propagation Letters, vol. 16, pp. 258-261, 2017.

[3] RongLin Li, D. C. Thompson, J. Papapolymerou, J. Laskar and M. M. Tentzeris, "A circularly polarized short backfire antenna excited by an unbalance-fed cross aperture," IEEE Transactions on Antennas and Propagation, vol. 54, no. 3, pp. 852-859, March 2006.

[4] Y. Li, S. Sun and F. Yang, "A Miniaturized Yagi-Uda-Oriented Double-Ring Antenna With Circular Polarization and Directional Pattern," in IEEE Antennas and Wireless Propagation Letters, vol. 12, pp. 945-948, 2013.

[5] S. Mohammadi-Asl, J. Nourinia, C. Ghobadi and M. Majidzadeh, "Wideband Compact Circularly Polarized Sequentially Rotated Array Antenna with Sequential-Phase Feed Network," in IEEE Antennas and Wireless Propagation Letters, vol. 16, pp. 3176-3179, 2017.

[6] C. Lu, M. K. Matters-Kammerer, A. Zamanifekri, A. B. Smolders and P. G. M. Baltus, "A Millimeter-Wave Tunable Hybrid-Transformer-Based Circular Polarization Duplexer With Sequentially-Rotated Antennas," in IEEE Transactions on Microwave Theory and Techniques, vol. 64, no. 1, pp. 166-177, Jan. 2016.

[7] Ratheesh. I, Midhum Joy, Amaljyothi, "Design and Performance Analysis of 4x1 Corporate Feed Circular Polarized Rectangular Microstrip Patch Antenna Using HFSS," International Journal of Engineering Research \& Technology (IJERT), vol. 3, Issue 9, 2014.

[8] B. Stec, A. Jeziorski, M. Czyżewski and A. Słowik, "Multielement patch antenna for K-band," 2012 13th International Radar Symposium, Warsaw, 2012, pp. 183-186, 2012.

[9] Ko Han Lu and The-Nan Chang, "Circularly polarized array antenna with corporate-feed network and series-feed elements," in IEEE Transactions on Antennas and Propagation, vol. 53, no. 10, pp. 3288-3292, Oct. 2005.

[10] D. F. Mona, D. C. Nascimento, "Available Universe of Input Impedances for the Probe-Fed Circularly Polarized Microstrip Antenna", in IEEE Intrnational Symposium on Antennas and Propagation \& USNC/URS/ National Radio Science Meeting, Sao Jose dos Campos, Brazil, vol. 25, pp. 978-1-5386-7102-3. 2018.

[11] G. L. Huang, S. G. Zhou, T. H. Chio, H. T. Hui, and T. S. Yeo, "A low profile and low sidelobe wideband slot antenna array feb by an amplitude-tapering waveguide feed-network," IEEE Trans. Antennas Propag., vol. 63, no. 1, pp. 419-423, Jan. 2015.

[12] S.-G. Zhou, Z.-H. Peng, G.-L. Huang, J.-Y. Li, and C.-Y.-D. Sim, "Design of wideband and dual-polarized cavity antenna planar array," IEEE Trans. Antennas Propag., vol. 64, no. 10, pp. 4565-4569, Oct. 2016.

[13] S.-G. Zhou, Z.-H. Peng, and C.-Y.-D. Sim, "A low-profile, dual-polarized, and wideband square cavity-backed antenna," Int. J. RF Microw. Comput.-Aided Eng., vol. 26, no. 8, pp. 724-730, Oct. 2016.

[14] G.-L. Huang, S.-G. Zhou, T.-H. Chio, and T.-S. Yeo, "Fabrication of a high-efficiency waveguide antenna array via direct metal laser sintering," IEEE Antennas Wireless Propag. Lett., vol. 15, pp. 622-625, 2016.

[15] S. Karimkashi and G. Zhang, "A dual-polarized series-fed microstrip antenna array with very high polarization purity for weather measurements," IEEE Trans. Antennas Propag., vol. 61, no. 10, pp. 5315-5319, Oct. 2013.

[16] F. Y. Zulkifli, T. Hidayat, Basari and E. T. Rahardjo, "Sidelobe level suppression using unequal four-way power divider for proximity coupled microstrip antenna," 2013 Asia-Pacific Microwave Conference Proceedings (APMC), Seoul, 2013, pp. 1166-1168.

[17] F. Y. Zulkifli, Y. Wahyu, Basari, E. T. Rahardjo, "Microstrip antenna array for coastal surveillance radar", Jurnal Elektronika dan Telekomunikasi, vol. 13, no. 2, Desember 2013.

[18] S. Karimkashi et al., "Dual-polarization frequency scanning microstrip array antenna with low cross-polarization for weather measurements," IEEE Trans. Antennas Propag., vol. 61, no. 11, pp. 5444-5452, Nov. 2013.

[19] G.-L. Huang, S.-G. Zhou, T.-H. Chio, and T.-S. Yeo, "Dual-polarized wideband and high-gain array with the waveguide-to-stripline series-feed network," in Proc. 8th Eur. Conf. Antennas Propag. (EuCAP), pp. 650-652, Apr. 2014.

[20] G.-L. Huang, S.-G. Zhou, T.-H. Chio, C.-Y.-D. Sim, and T.-S. Yeo, "Wideband dual-polarized and dual-monopulse compact array for SAR system integration applications," IEEE Geosci. Remote Sens. Lett., vol. 13, no. 8, pp. 12031207, Aug. 2016. 
[21] H. Guan-Long, Z. Shi-Gang, C. Tan-Huat, and Y. Tat-Soon, "Broadband and high gain waveguide-fed slot antenna array in the Ku-band," Microw., Antennas Propag., vol. 8, no. 13, pp. 1041-1046, Oct. 2014.

[22] Guang Long Huang, Shi Gang Zhou, Tan Huat Chio, Chow Yen Desmond Sim and Tat Soon Yeo, "Waveguide Stripline Series-Corporate Hybrid Feed Technique for Dual Polarized Antenna Array Applications", IEEE Transactions on Components, Packaging and Manufacturing Technology, vol. 7, no. 1, 2017.

[23] M. Hajian, J. Zijderveld, A. A. Lestari and L. P. Ligthart, "Analysis, design and measurement of a series-fed microstrip array antenna for X-band INDRA: The INDonesian maritime RAdar," 2009 3rd European Conference on Antennas and Propagation, Berlin, 2009, pp. 1154-1157.

[24] Y. Ushijima, E. Nishiyama, and M. Aikawa, "Single-layer integrated microstrip array antenna for dual circular polarisation," Microw., Antennas Propag., vol. 6, no. 8, pp. 962-968, Jun. 2012.

[25] E. T. Rahardjo, D. P. Yusuf, Basari and F. Y. Zulkifli, "Microstrip array antenna for X-band radar application," 2015 Asia-Pacific Microwave Conference (APMC), Nanjing, 2015, pp. 1-3.

[26] H. S. Setiadji, F. Y. Zulkifli and E. T. Rahardjo, "Radiation characteristics of Microstrip Array Antenna for X-Band Radar application," 2016 Progress in Electromagnetic Research Symposium (PIERS), Shanghai, 2016, pp. 39923995.

\section{BIOGRAPHY OF AUTHORS}

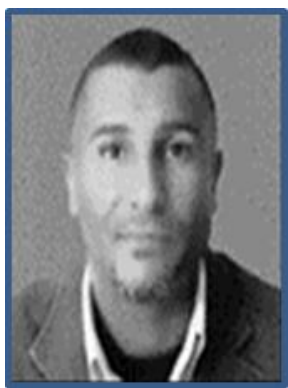

Taher Khalifa Taher received and obtained Bachelor and Master of Science in Engineering (Command and Engineering Radiotechnical and Sonar, Means of Surface Ships and Signal Processing and Telecommunications), from the Caspian Higher Naval Red- Banner University in Union of Soviet Socialist Republics in June 1992. He was a Communications Engineering Staff in the Libyan Navy. A lecturer at the Libyan Naval Higher Studies College from 1998 to 2003. Furthermore, he participated in some of the scientific seminars with the Italian, French and Egyptian side on search and rescue, 2004-2007. Currently, He is a Ph.D student at Institute of Graduate Studies (IGS), SEGi University, Kota Damansara, Malaysia since Sep. 2015.

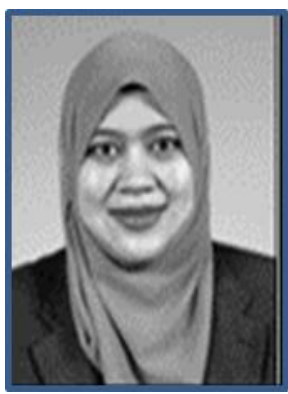

Nurulazlina Ramli received the B.Eng. degree in Electrical Engineering (Telecommunication) from the Universiti Teknologi Malaysia (UTM), Malaysia, in 2008, the M.Sc. degree in Telecommunication and Information Engineering, and the Ph.D. degree in Electrical Engineering (specialization in radio frequency and microwave technology) with the Antenna Research Center (ARC), from the Universiti Teknologi Mara (UiTM), Shah Alam, Malaysia, in 2011 and 2015, respectively. Currently, she is a Lecturer with the Faculty of Engineering and Built Environment (FoEBE), SEGi University, Kota Damansara, Malaysia since Sept. 2015. Between July 2008 and December 2009, she was a Postgraduate Assistant (Tutor) with the Faculty of Electrical Engineering, Universiti Teknologi Petronas (UTP), Sri Iskandar, Perak, Malaysia. She has authored several journal articles and conference papers. Her research interests include the areas of communication antenna design, electromagnetic radiation analysis, indoor/outdoor propagation modeling, radio astronomy antennas, and satellite antennas.

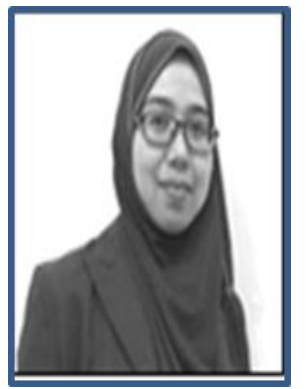

Norsuzlin Mohd Sahar was born in Melaka, Malaysia in 1981. She obtained a BEng degree in Communication Engineering from International Islamic University Malaysia (IIUM) in 2006 and MEng in Universiti Teknologi Malaysia(UTM) in 2010. She received a PhD degree for research in reconfigurable antenna using RF MEMs switches for RFID and GPS applications from the Universiti Kebangsaan Malaysia(UKM) in 2016. She held the lecturing position at USCI University and SEGi University for several years. Currently, she is a Senior Lecturer at Space Science Centre (ANGKASA), Institute of Climate Change, UKM. Her research interest is in microwave device for wireless application and system particularly in broadband microstrip antennas and reconfigurable antennas. 